\title{
Ciclo biológico e predação de três espécies de coccinelídeos (Coleoptera, Coccinellidae) sobre o pulgão-gigante-do-pinus Cinara atlantica (Wilson) (Hemiptera, Aphididae)
}

\author{
Nádia Cristina de Oliveira ${ }^{1}$, Carlos Frederico Wilcken ${ }^{1} \&$ Carlos Alberto O. de Matos ${ }^{1}$
}

${ }^{1}$ Departamento de Produção Vegetal, Faculdade de Ciências Agronômicas, Universidade Estadual Paulista. Caixa Postal 237, $18603-970$ Botucatu-SP, Brasil. Endereço eletrônico: nadcrys@fca.unesp.br; cwilcken@fca.unesp.br

\begin{abstract}
Biological cycle and predation of three coccinellid species (Coleoptera, Coccinellidae) on giant conifer aphid Cinara atlantica (Wilson) (Hemiptera, Aphididae). The aphids of the genus Cinara Curtis are important pests of conifers in several countries. In Brazil, Cinara atlantica (Wilson, 1919) has damaged commercial plantations of Pinus spp. and biological control with predators can be a better option than chemical control. The objective of this work was to study biology and predation potential of coccinellids Hippodamia convergens Guérin-Méneville, 1842, Cycloneda sanguinea (Linnaeus, 1763) and Eriopis connexa (German, 1824) (Coleoptera, Coccinellidae) on nymphs of C. atlantica. The study was carried out under controlled conditions (temperature: $23+1{ }^{\circ} \mathrm{C}$, RH: $70+10 \%$ and fotophase: $14 \mathrm{~h}$ ). It was verified that C. atlantica nymphs are adequate as food for the three coccinellid species, assuring their development and reproduction. $H$. convergens and $C$. sanguinea presented higher longevity and reproduction capacity and also higher predation capacity (3832 and 3633 nymphs of $C$. atlantica against 2735 nymphs consumed by E. connexa during the complete cycle, respectively for the species). These predator species can contribute to the reduction of Cinara population in the field.
\end{abstract}

KEYWORDs. Biological control; forest protection; giant conifer aphids; Pinus.

Resumo. Afídeos do gênero Cinara Curtis são importantes pragas de coníferas em vários países. No Brasil Cinara atlantica (Wilson, 1919) tem causado danos em plantações comerciais de Pinus spp. e o controle biológico com predadores pode ser uma opção melhor que o controle químico. Este trabalho teve por objetivo estudar a biologia e a capacidade de predação dos coccinelídeos Hippodamia convergens Guérin-Méneville, 1842, Cycloneda sanguinea (Linnaeus, 1763) e Eriopis connexa (German, 1824) (Coleoptera, Coccinellidae) sobre ninfas de C. atlantica. O estudo foi conduzido sob condições controladas (temperatura: $23+1{ }^{\circ} \mathrm{C}$, UR: $70+10 \%$ e fotofase: $14 \mathrm{~h}$.). Foi verificado que ninfas de C. atlantica são adequadas como alimento para as três espécies de coccinelídeos, assegurando seu desenvolvimento e reprodução. $H$. convergens e $C$. sanguinea apresentaram maior longevidade e capacidade de reprodução e também maior capacidade de predação (3832 e 3633 ninfas de C. atlantica em comparação a 2735 ninfas consumidas por $E$. connexa durante o ciclo completo, respectivamente para as espécies). Estas espécies de predadores podem contribuir para a redução da população de Cinara no campo.

Palavras-Chave. Controle biológico; Pinus; proteção florestal; pulgão-gigante-do-pinus.

Muitos pulgões são pragas conhecidas em áreas florestais (Drees 1993). Os afídeos do gênero Cinara Curtis são importantes pragas de Pinus spp. (Pinaceae) em diversos países (BLACKMAN \& EASTOP 1994).

No Brasil, no ano de 1996, foi detectada a presença de afídeos deste gênero atacando povoamentos de Pinus spp. (Penteado et al. 2000). Atualmente estes afídeos vêm causando danos consideráveis às florestas de Pinus spp. nos estados de Santa Catarina, Paraná, São Paulo e Minas Gerais, confirmando que os pulgões podem ser considerados pragas potenciais quando existem condições favoráveis à sua reprodução.

As plantas atacadas por Cinara spp. apresentam clorose, deformação e queda de acículas, redução no desenvolvimento da planta, entortamento do fuste e superbrotação devido à destruição do broto apical (PENTEAdo et al. 2000).

O controle biológico de insetos ocupa uma posição importante dentro dos programas de Manejo Integrado de Pragas, pois, além de atuar de forma harmoniosa com o meio ambiente, é um método eficiente principalmente quando associado a outras medidas de controle.
COULSON \& Witter (1984) referem-se aos coleópteros da família Coccinellidae como importantes predadores de afídeos que atacam espécies florestais. Segundo Hodeк (1973), as larvas e adultos de coccinelídeos apresentam entre as características positivas uma grande atividade de busca pelo alimento, ocupam todos os ambientes de suas presas e são muito vorazes.

A ocorrência natural de larvas e adultos de coccinelídeos durante o período de infestação dos pulgões nas diferentes culturas diminui suas populações e reduz os danos provocados pelos mesmos (SANTOS 1992). As larvas alimentam-se de pulgões, ingerindo o líquido do corpo e deixando o tegumento como resíduo, enquanto o adulto devora totalmente o pulgão sem deixar vestígios.

Segundo Hagen et al. (1976), vários fatores podem ser importantes para a determinação do potencial desses predadores como agentes de controle biológico, incluindo o consumo alimentar e variáveis ambientais sobre as populações tanto dos afídeos, quanto do predador.

Os alimentos dos coccinelídeos predadores podem ser classificados em essenciais e alternativos, os essenciais 
asseguram o desenvolvimento e a oviposição, enquanto os alternativos apenas prolongam a sobrevivência do inseto (Hodek 1973).

A qualidade e a quantidade de afídeos consumidos pelos coccinelídeos pode influenciar o período de pré-oviposição e a fecundidade destes (HAGEN \& Berubé 1950; El Hariri 1966 apud Hagen \& Van Den Bosch 1968). De acordo com CANARD \& PrinciPI (1984), a qualidade e a quantidade da presa oferecida é fundamental no desenvolvimento dos predadores, podendo induzir a diferentes taxas de mortalidade. Assim sendo, apesar dos predadores serem generalistas, apresentam preferências alimentares por presas que facilitem o seu desenvolvimento, ou que lhes permita completarem o ciclo de vida.

No Brasil, em plantações de Pinus spp. infestadas com Cinara spp. tem sido registrada a presença de predadores pertencentes à família Coccinellidae (Penteado et al. 2000). No entanto, pouco se sabe do potencial biológico desses predadores sobre os pulgões-gigantes-do-pinus. Portanto, este trabalho teve por objetivo estudar a biologia e avaliar o potencial de predação das espécies de coccinelídeos Hippodamia convergens Guérin-Méneville, 1842, Cycloneda sanguinea (Linnaeus, 1763) e Eriopis connexa (German, 1824) sobre ninfas de Cinara atlantica (Wilson, 1919).

\section{MATERIAL E MÉTODOS}

Técnica geral. $\mathrm{O}$ experimento foi conduzido de janeiro a julho de 2002, em sala climatizada com temperatura de $23+1{ }^{\circ} \mathrm{C}$, umidade relativa de $70+10 \%$ e fotofase de 14 horas.

Adultos de $H$. convergens, $C$. sanguinea e E. connexa foram obtidos no campo (Buri, SP) em plantas de Pinus taeda (L.) infestadas com $C$. atlantica. Desses adultos obteve-se as posturas e destas, foram obtidas 50 larvas recém-eclodidas de cada espécie, as quais foram individualizadas para os experimentos.

Para avaliar o desenvolvimento dos diferentes estágios biológicos (ovo, larva, pupa e adulto), as larvas das três espécies foram criadas em placas de petri plásticas de $6,0 \mathrm{~cm}$ de diâmetro e 2,0 cm de altura, forradas com papel filtro para manutenção da umidade adequada e local de oviposição. A cada dois dias as larvas eram transferidas para outra placa, procedendo-se novamente o umedecimento do ambiente com água destilada.

As ninfas de $C$. atlantica usadas como alimento foram coletadas diretamente no campo em plantas de $P$. taeda. No laboratório, as ninfas eram cuidadosamente retiradas dos ramos com auxílio de pincel e transferidas para as placas com os predadores. Durante os estágios de larva e adulto foram oferecidas inicialmente 45 ninfas/dia para cada indivíduo, repondo as que eram consumidas para manter a mesma quantidade diária.

Os dados referentes ao ciclo biológico foram submetidos à análise comparativa descritiva (médias + erro padrão) entre as espécies estudadas. Os dados obtidos referentes à predação foram submetidos à análise de variância e as médias comparadas pelo teste de Tukey $(\mathrm{P}>0,05)$; a variável predação diária na fase adulta foi analisada pelo teste de Nemenyi $(\mathrm{P}>0,05)$.

\section{Desenvolvimento biológico}

Ovo. Diariamente, após a contagem dos ovos, as posturas obtidas de cada casal foram transferidas para outra placa devidamente identificada, onde permaneceram sob observação até a eclosão das larvas, avaliando-se o número de ovos por postura, período embrionário e a viabilidade dos ovos para cada espécie. Nesta fase foram avaliadas 30 posturas de 20 fêmeas/espécie $(n=600)$.

Larva. No segundo dia após a eclosão, procedeu-se à individualização das larvas e transferência destas para novas placas de criação onde recebiam as 45 ninfas de $C$. atlantica como presas. Para a medição diária da cápsula cefálica utilizouse ocular micrométrica acoplada ao microscópio estereoscópio com aumento de 40 vezes. Durante esta fase avaliou-se a duração e viabilidade larval $(n=50)$, número de ínstares e duração de cada ínstar $(\mathrm{n}=20)$ para cada espécie.

Pupa. No último ínstar larval, assim que se observou redução na movimentação das larvas, procedeu-se à transferência desses indivíduos para novas placas de criação. Nesta fase, foi avaliado o período e viabilidade pupal para cada espécie.

Adulto. Após a sexagem, pela observação de características morfológicas externas dos adultos recém-emergidos, estes foram separados em casais. No decorrer desta fase avaliou-se a razão sexual $(n=50)$, longevidade $(n=50)$. A sexagem dos adultos foi feita pela observação das características citadas por IPERTI (1999).

Ciclo total. Determinou-se o ciclo total (período larval + pupal + longevidade dos adultos) levando em consideração os dados obtidos para 50 repetições de cada espécie.

Capacidade de predação. A predação de ninfas de $C$. atlantica pelos coccinelídeos foi avaliada a cada 24 horas como sendo a diferença diária entre o número de ninfas oferecidas e o número de ninfas remanescentes. Foi determinado o consumo total e diário durante a fase larval $(n=50)$ e adulta $(n=50)$ obtendo-se assim o consumo durante o ciclo total (larva + adulto).

\section{RESULTADOS E DISCUSSÃO}

Estágios larval e pupal. Durante estas fases, as três espécies apresentaram alta viabilidade. Provavelmente, o fato da individualização das larvas ter sido realizada somente no segundo dia após a eclosão pode ter sido suficiente para evitar a mortalidade devido a ferimentos causados pelo manuseio. De acordo com MACHADO (1982), este procedimento não deve ser feito no primeiro dia, porque eleva a mortalidade das larvas de primeiro ínstar.

As larvas das três espécies estudadas são do tipo campodeiforme e, de uma maneira geral, demonstraram grande capacidade de fixação na superfície através da extremidade do abdome principalmente durante a muda. Nessa ocasião, fixavam-se de cabeça para baixo e assim permaneciam até completar o processo. Momentos antes de sofrerem a muda, as 
Tabela I. Tempo de desenvolvimento (média + erro padrão) dos diferentes estágios biológicos de Hippodamia convergens, Cycloneda. sanguinea e Eriopis connexa alimentados com ninfas de Cinara atlantica (temperatura: $23+1^{\circ} \mathrm{C}$, UR $70+10 \%$ e fotofase: $14 \mathrm{~h}$ ).

\begin{tabular}{lccc}
\hline \multirow{2}{*}{ Fases biológicas } & \multicolumn{2}{c}{ Tempo de desenvolvimento (dias) } \\
\cline { 2 - 4 } & H. convergens & C. sanguinea & E. connexa \\
\hline Instares (n=20) & $2,9+0,11$ & & \\
I & $2,2+0,08$ & $2,5+0,11$ & $3,1+0,08$ \\
II & $2,6+0,10$ & $1,8+0,12$ & $2,2+0,09$ \\
III & $3,1+0,09$ & $1,9+0,12$ & $2,5+0,11$ \\
IV & $10,78+0,07$ & $2,7+0,10$ & $3,0+0,12$ \\
& & $9,04+0,08$ & $10,82+0,13$ \\
Estágio larval (n=50) & $6,58+0,09$ & $6,08+0,15$ & $(100 \%)$ \\
Estágio pupal (n=50) & $(100 \%)$ & $(100 \%)$ \\
(viabilidade) & $115,20+3,35$ & $125,70+3,12$ & $108,08+4,60$ \\
Estágio adulto (n=50) & $132,56+3,35$ & $140,82+3,16$ & $124,64+4,60$ \\
Ciclo total (larva + pupa + adulto) $(\mathrm{n}=50)$ & $3,90+0,01$ & $3,95+0,01$ & $3,96+0,00$ \\
\hline $\begin{array}{l}\text { Incubação dos ovos }{ }^{1} \\
\text { Número de ovos/postura } \\
\text { (viabilidade dos ovos) }\end{array}$ & $22,4+0,44$ & $21,8+2,20$ & $19,1+0,63$ \\
\hline
\end{tabular}

${ }^{1} n=600$

larvas diminuíam a alimentação e movimentavam-se pouco.

As pupas das três espécies (H. convergens, $C$. sanguinea e E. connexa) permaneceram presas pelo abdome à superfície do recipiente de criação. As características das pupas das espécies estudadas concordam com a descrição feita por CosTA et al. (1988), que afirmam que as pupas dos coccinelídeos são geralmente esclerotizadas, coloridas e permanecem parcialmente encobertas pelo tegumento larval.

De maneira geral, as larvas das três espécies apresentaram quatro ínstares concordando com as observações de HoDeK (1973) para a maioria das espécies de coccinelídeos.

No primeiro e terceiro ínstares, $C$. sanguinea apresentou tempo menor no desenvolvimento em comparação com $H$. convergens e E. connexa (Tabela I). Observou-se, ainda, que as três espécies apresentaram maior duração no tempo de desenvolvimento no último ínstar. Segundo Machado (1982), esse período mais longo ocorre para que os indivíduos possam suprir as necessidades de substâncias nutritivas exigidas para a transformação em pupa e posterior emergência dos adultos.

O período total do desenvolvimento larval foi semelhante entre os indivíduos de $H$. convergens e E. connexa (Tabela I). Nestas condições, os indivíduos de $C$. sanguinea foram os que, em média, apresentaram tempo menor para completar o estágio larval.

Veloso et al. (1995) constataram que, à temperatura de $23^{\circ} \mathrm{C}$, as larvas de C. sanguinea completaram o desenvolvimento em 9,43 dias, resultado semelhante ao encontrado para $C$. sanguinea no presente trabalho (9,04 dias). Santos \& Pinto (1981) e BотеLно et al. (1992) também encontraram valores próximos.

Gurney \& Hussey (1970) encontraram que, para larvas de
C. sanguinea alimentadas com o pulgão Myzus persicae Sulzer, sob temperatura de $24^{\circ} \mathrm{C}$, o tempo médio total de desenvolvimento foi de 15 dias.

CARDoso \& LAzZARI (2003) estudaram a biologia de duas espécies de Coccinellidae alimentadas com ninfas de Cinara spp. nas temperaturas de $20^{\circ} \mathrm{C}$ e $25^{\circ} \mathrm{C}$. Nestas condições, o período médio de desenvolvimento larval de $C$. sanguinea foi de 15,8 e de 8 dias, respectivamente, e para $H$. convergens, 19,2 e 10,9 dias nestas temperaturas, respectivamente.

Veloso et al. (1995) verificaram que a $23^{\circ} \mathrm{C}$ o desenvolvimento pupal de C. sanguinea foi de 5,72 dias, resultado também próximo ao encontrado para a espécie neste trabalho (5,74 dias).

Para C. sanguinea alimentada com Cinara spp., CARDOso \& LAZZARi (2003) observaram o tempo de desenvolvimento pupal de 8,2 e 4,7 dias a $20^{\circ} \mathrm{Ce} 25^{\circ} \mathrm{C}$, respectivamente, e para $H$. convergens um período de desenvolvimento de 11,1 e 6,3 dias, respectivamente.

Estágio adulto. A razão sexual encontrada foi de 0,5 para $H$. convergens, 0,46 para $C$. sanguinea e 0,46 para $E$. connexa, com uma proporção macho:fêmea de 1:1; 1:1,17 e 1:1,17, respectivamente.

Verificou-se que nas condições ambientais deste estudo, independentemente do sexo, a longevidade dos adultos de $C$. sanguinea foi maior que a das outras duas espécies (Tabela I). Os adultos de E. connexa apresentaram, em média, menor longevidade em relação aos adultos de $C$. sanguinea e $H$. convergens, concordando com HoDEK (1973) que afirma que a longevidade dos coccinelídeos é variável entre as espécies. 
Tabela II. Predação diária e total (média + erro padrão) de ninfas Cinara atlantica por larvas e adultos de Hippodamia convergens, Cycloneda sanguinea e Eriopis connexa (temperatura: $23+1{ }^{\circ} \mathrm{C}$, UR $70+10 \%$ e fotofase: $14 \mathrm{~h}$ ).

\begin{tabular}{|c|c|c|c|c|c|}
\hline \multirow{2}{*}{ Espécies } & \multicolumn{2}{|c|}{ Estágio larval } & \multicolumn{2}{|c|}{ Estágio adulto } & \multirow{2}{*}{ Predação total ${ }^{1}$} \\
\hline & diária $^{1}$ & total $^{1}$ & diária $^{1}$ & total $^{1}$ & \\
\hline H. convergens & $27,99+0,32 \mathrm{a}$ & $301,38+3,48 \mathrm{a}$ & $31,27+1,05 \mathrm{a}$ & $3505,6+97,04 \mathrm{a}$ & $3832,5+101,51 a$ \\
\hline C. sanguinea & $23,63+0,35 b$ & $213,30+3,37 \mathrm{c}$ & $27,71+0,99 b$ & $3394,7+101,90 a$ & $3633,5+97,17 \mathrm{a}$ \\
\hline \multirow[t]{2}{*}{ E. connexa } & $21,30+0,37 \mathrm{c}$ & $229,62+3,99 b$ & $31,03+7,79 a$ & $2480,7+93,72 b$ & $2735,8+94,06 b$ \\
\hline & $\begin{array}{c}\mathrm{CV}(\%) 10,26 \\
\mathrm{~F}=100,5 \\
\mathrm{P}>0,0001\end{array}$ & $\begin{array}{c}\mathrm{CV}(\%) 23,93 \\
\mathrm{~F}=166,49 \\
\mathrm{P}>0,0001\end{array}$ & $\begin{array}{c}C V(\%) 14,16 \\
\chi^{2}=41,37 \\
P>0,0001\end{array}$ & $\begin{array}{c}\mathrm{CV}(\%) 22,07 \\
\mathrm{~F}=33,20 \\
\mathrm{P}>0,0001\end{array}$ & $\begin{array}{c}\mathrm{CV}(\%) 20,30 \\
\mathrm{~F}=36,81 \\
\mathrm{P}>0001\end{array}$ \\
\hline
\end{tabular}

${ }^{1}$ Médias seguidas da mesma letra nas colunas não diferem entre si pelo teste de Tukey $(\mathrm{P}>0,05)$

${ }^{2}$ Médias seguidas da mesma letra na coluna não diferem entre si pelo teste de Nemenyi $(P>0,05)$

Desenvolvimento embrionário. Os períodos médios de desenvolvimento embrionário para os ovos de $H$. convergens (3,90 dias), C. sanguinea (3,95 dias) e E. connexa (3,96 dias) foram semelhantes e ficaram próximos ao período médio de 3 dias obtido por Veloso et al (1995), a $23^{\circ} \mathrm{C}$ para $C$. sanguinea.

A viabilidade encontrada para os ovos foi de $83,49 \%$ para $H$. convergens, $83,13 \%$ para $C$ sanguinea e $64,7 \%$ para $E$. connexa.

CARdoso \& LÁzzARI (2003) registraram para ovos de $C$. sanguinea alimentadas com Cinara spp., o período médio de incubação de 5 e 4 dias, respectivamente a $20^{\circ} \mathrm{C}$ e $25^{\circ} \mathrm{C}$.

GuRNEY \& HusSEy (1970) encontraram um período médio de incubação para os ovos de C. sanguinea de 3 dias para a temperatura de $21^{\circ} \mathrm{C}$, e 2 dias a $24^{\circ} \mathrm{C}$. De acordo com BALduF (1935), o período de incubação do ovo desta espécie é de 3 a 5 dias, com uma média de 4 dias, resultados estes próximos ao encontrado neste trabalho.

Para ovos de C. sanguinea mantidos sob a temperatura de $23^{\circ} \mathrm{C}$, Veloso et al. (1995) encontraram a viabilidade média de $86 \%$, resultado próximo ao encontrado para $H$. convergens e $C$. sanguinea, nesta pesquisa.

Predação no estágio larval. Comparando-se as médias obtidas, foi observado que estas diferiram significativamente entre as espécies estudadas. H. convergens apresentou o maior consumo diário, seguido por $C$. sanguinea, sendo que $E$. connexa, apresentou a menor média diária de consumo (Tabela II).

Com relação à predação total nesta fase, $H$. convergens também apresentou o maior consumo. E. connexa apresentou a segunda maior média, seguida por $C$. sanguinea. Contudo, se também for levado em consideração o período larval (dias) destas duas espécies (Tabela I), C. sanguinea tende a ter um maior potencial de consumo devido ao fato de ter apresentado a média diária superior à de E. connexa (Tabela II).

A capacidade média da predação total na fase larval obtida para $H$. convergens neste trabalho $(301,38)$, foi próxima à obtida por SweEtman (1958) o qual relatou que esta espécie consome em seu estágio larval, de 200 a 500 afídeos.

CARDOSO \& LÁzZARI (2003) verificaram que em toda a fase larval, nas temperaturas de $15^{\circ} \mathrm{C}, 20^{\circ} \mathrm{C}$ e $25^{\circ} \mathrm{C}, H$. convergens teve um consumo médio de 187,1; 205,1 e 216,6 ninfas (de tamanho médio) de Cinara spp.. Para C. sanguinea, os autores constataram o consumo de 121,3; 140,4 e 109,9 afídeos, nas mesmas temperaturas, respectivamente.

Para C. sanguinea, Hodek (1973) verificou que o consumo médio na fase larval foi de 320, 292 e 205 pulgões nas temperaturas de $16^{\circ} \mathrm{C}, 20^{\circ} \mathrm{C}$ e $24^{\circ} \mathrm{C}$, respectivamente. Estes resultados foram próximos aos encontrados nesta pesquisa (213,30 ninfas de C. atlantica).

Predação no estágio adulto. Foi constatada diferença significativa na predação de $C$. atlantica pelos adultos das três espécies de joaninhas (Tabela II). Diariamente, os adultos de $H$. convergens consumiram uma quantidade média de afídeos semelhante à $E$. connexa, não havendo diferença significativa entre estas duas espécies as quais, no entanto, apresentaram a média diária de predação na fase adulta superior e significativamente diferente à de $C$. sanguinea.

Pela comparação de predação obtida por indivíduo durante toda a fase adulta, notou-se que $E$. connexa obteve média total inferior às médias de predação obtidas pelas outras duas espécies estudadas (Tabela II), este fato está relacionado às espécies terem apresentado menor longevidade (Tabela I).

SwEETMAN (1958) relatou que $H$. convergens, durante toda a fase adulta, chega a consumir de 3000 a 6000 . Os resultados obtidos para a predação total de ninfas de $C$. atlantica pelos adultos de $H$. convergens $(3505,6)$ e $C$. sanguinea $(3394,7)$ enquadram-se nos níveis de consumo mencionado por aquele autor.

Predação total (larva + adulto). Entre as espécies de 
joaninhas estudadas, $E$. connexa predou a menor quantidade de ninfas de $C$. atlantica durante o ciclo biológico total, diferindo de $H$. convergens e $C$. sanguinea que apresentaram as médias de predação significativamente maiores (Tabela II).

Os resultados obtidos neste trabalho demonstraram que ninfas de $C$. atlantica são adequadas como alimento para as três espécies de coccinelídeos assegurando o desenvolvimento e oviposição. As larvas e adultos de $H$. convergens, $C$. sanguinea e E. connexa, que ocorrem naturalmente durante o período de infestação de $C$. atlantica em $P$. taeda, podem contribuir de maneira importante no controle biológico natural desta praga, pois diminuem a população do pulgão através da predação, colaborando assim, para a redução dos danos provocados por esses afídeos.

De acordo com HaGen et al. (1976), vários fatores podem ser importantes para determinar o potencial desses predadores como agentes de controle biológico, incluindo comportamento de busca pela presa, preferência e consumo alimentar, impacto de outros agentes naturais de controle e variáveis ambientais sobre a população de ambos, afídeos e predadores. No entanto, nas condições laboratoriais em que foi conduzido este trabalho (temperatura: $23+1{ }^{\circ} \mathrm{C}$, UR $70+10 \%$ e fotofase: $14 \mathrm{~h}$ ), $H$. convergens e $C$. sanguinea destacaram-se por apresentar maior longevidade e maior capacidade reprodutiva e de predação sobre as ninfas de $C$. atlantica em comparação à $E$. connexa.

Agradecimentos. Ao CNPq pela bolsa de mestrado concedida ao primeiro autor. À empresa Orsa Celulose, Papel e Embalagens S/A por permitir a condução dos experimentos em sua propriedade. À Dra. Regina Célia Zonta de Carvalho pela identificação da espécie Cinara atlantica.

\section{REFERÊNCIAS}

Balduf, W. V. 1935. The bionomics of entomophagous Coleoptera. St. Louis, Jonh S. Swift, 220 p.

Blackman, R. L. \& V. F. Eastop. 1994. Aphids on the world's trees. New York, John Wiley \& Sons, 986 p.

Botelho, A. C. B.; T. M. SAntos \& J. M. WAQuil. 1992. Biologia da joaninha Cycloneda sanguinea (L., 1763) (Col: Coccinellidae) em pulgão verde Schizaphis graminum (Rond., 1852) obtidos em sorgo. Relatório Técnico Anual do CNPMS- 1988-1999. Sete Lagoas, EMBRAPA, $247 \mathrm{p}$.

Canard, M. \& M. M. Principi. 1984. Development of Chrysopidae, p. 57 - 75. In: M. Canard; Y. Séméria \& T. R. New (eds). Biology of Chrysopidae. The Hague, W. Junk Publishers, 294 p.

Cardoso, J. T. \& S. M. N. Lazzari. 2003. Consumption of Cinara spp. (Hemiptera; Aphididae) by Cycloneda sanguinea (Linnaeus, 1763) and Hippodamia convergens Guérin-Méneville, 1842 (Coleoptera, Coccinellidae). Revista Brasileira de Entomologia 47(4): 559562 .

Cardoso, J. T. \& S. M. N. LÁzzari. 2003. Comparative biology of Cycloneda sanguinea (Linnaeus, 1763) and Hippodamia convergens Guérin-Méneville, 1842 (Coleoptera, Coccinellidae) focusing on the control of Cinara spp. (Hemiptera, Aphididae). Revista Brasileira de Entomologia 47(3): 443-446.

Costa, C.; A. S. Vanin \& S. A. CASARI-Chen. 1988. Larvas de Coleoptera do Brasil. São Paulo, Museu de Zoologia-USP e FAPESP, 282 p.

Coulson, R. N \& J. A. WitTER. 1984. Principles of population modification and regulation using artificial and natural agents, p. 193-251. In: R. N. Coulson \& J. A. Witter. Forest entomology: ecology and management. New York, John Wiley \& Sons, 669 p.

Drees, B. M. Aphid management [on line]. Texas: Texas Agricultural Extension Service, 1993. [data de acesso: 01 jul 2000]. Available from: World Wide Web: <URL: http://entowww.tamu.edu/extension/ bulletins/uc/uc-031.html.

GuRney, B. \& N. W. Hussey. 1970. Evalution of some coccinellid species for the biological control of aphids in protected cropping. Annals of Applied Biology 65: 451- 458 .

Hagen, K. S \& R. Van Den Bosch. 1968. Impact of pathogens, parasites and predators on aphids. Annual Review of Entomology 13: 325384.

Hagen, K. S.; S. Bombosch \& J. A. McMurtry. 1976. The biology and impact of predators, p. 93-142. In: C. B. HufFaKer \& P. S. MESSENGER. Theory and Practice Biological Control. New York, Academic Press, $788 \mathrm{p}$.

Hodek, I. 1973. Biology of Coccinellidae. Prague, Academic of Sciences, $260 \mathrm{p}$.

IPERTI, G. 1999. Biodiversity of predaceous Coccinellidae in relation to bioindication and economic importance. Agriculture Ecosystems and Environment 74: 323-342.

Machado, V. L. R. 1982. Morfologia e aspectos biológicos de Olla vnigrum (Mulsant, 1866) e Cycloneda conjugata Mulsant, 1850 (Col., Coccinellidae) predadores de Psylla sp. (Homoptera, Psyllidae) em sibipiruna (Caesalpinia pelthophoroides Benth). Dissertação de Mestrado. Piracicaba, Escola Superior de Agricultura "Luiz de Queiroz" - Universidade de São Paulo, 61 p.

Penteado, S. R. C.; R. F. Trentini; E. T. Iede \& W. R. Filho. 2000. Ocorrência, distribuição, danos e controle de pulgões do gênero Cinara em Pinus spp. no Brasil. Revista Floresta 30(1/2): 55-64.

Santos, G. P. \& A. C. Q. Pinto. 1981. Biologia de Cycloneda sanguinea e sua associação com pulgão em mudas de mangueira. Pesquisa Agropecuária Brasileira 16(4): 473-76.

Santos, T. S. 1992. Aspectos morfológicos e efeito da temperatura sobre a biologia de Scymnus (Pullus) argentinicus (Weise, 1906) (Coleoptera: Coccinellidae) alimentados com pulgão verde Schizaphis graminum (Rondani, 1852) (Homoptera: Aphididae). Dissertação de Mestrado. Lavras, Escola Superior de Agricultura de Lavras, $105 \mathrm{p}$.

Sweetman, H. L. 1958. Principles of biological control. Duduque. WMC. Brown, 560 p.

Veloso, V. R.; R. V. Naves.; J. L. Nascismento.; P. M. Fernandes \& A. H. Garcia. 1995. Aspectos biológicos de Cycloneda sanguinea (L.) (Coleoptera, Coccinellidae). Anais da Escola de Agronomia e Veterinária 25(2): 123-127. 